\title{
A docência como profissão e objeto de pesquisa
}

\author{
Helena Faria de Barros
}

Doutora em Educaçāo - UNESP, Presidente Prudente-SP. Livre Docente - Universidade Federal de Santa Maria-RS. Coordenadora do Mestrado em Educação - UCDB - Campo Grande-MS.

O texto que segue constitui parte da justificativa do Programa de Mestrado em Educaçāo - Formaçāo de Professores da Universidade Católica Dom Bosco de Campo Grande (instituiçāo promotora) e das outras duas instituiçōes consorciadas: Faculdades Integradas de Dourados e Centro de Ensino Superior "Plínio Mendes de Souza" de Campo Grande. Ele pōe em destaque a relevância acadêmica da área de concentraçāo pela qual se optou.

A crise de qualidade por que passa hoje a educaçāo escolarizada tem suas raízes em fatores da macro-estrutura do sistema social, como os sócio-culturais e políticoeconômicos e, também, nos fatores intra-escolares. Há muito o que se tentar e qualquer alternativa de mudança deve considerar todos esses fatores e a complexidade do problema exige que sejam atingidos num escalonamento e ritmo bastante determinados e previstos. Seja qual for a tentativa de superaçāo da crise, por quais caminhos se decidir, nenhum deles pode ficar alheio ao professor. Pelo contrário, deve envolvê-lo sob o risco de todo o esforço se tornar infrutífero.

Nenhuma nova proposta deve ser "à prova de professor", isto é, nāo sensível a ele. 0 êxito de qualquer proposta é influenciado sempre pelos modos com que o professor incorpora e traduz a inovação no seu fazer diário. "Não é mais possível considerar os professores como uma variável de 'distúrbio'; eles devem ser vistos nāo somente como variáveis essenciais mas também como mediadores indispensáveis de todo processo de inovaçāo curricular", diz Pontecorvo.

Nāo se pode cair na posiçāo extrema da que centra nos professores toda a responsabilidade pela melhoria do ensino, mas parece essencial admitir que nenhuma mudança possa acontecer sem sua participaçāo e comprometimento.

Num momento em que se buscam inovaçōes criativas de superaçāo da crise em educaçāo, nada mais justo do que a ênfase e a opçāo pela - Formaçāo de Professores - como área de concentraçāo num curso de Mestrado em Educaçāo destinado, prioritariamente, ao aperfeiçoamento dos docentes das instituiçōes envolvidas.

Podem-se distinguir, na evoluçāo do processo de formaçāo de professores no 
Brasil, algumas fases que indicam a importância, a complexidade e a direçāo que o problema assume. Até a década de 60 , formar professores consistia em descobrir, para desenvolver, as qualidades a nível pessoal consideradas importantes por favorecerem um melhor relacionamento didático-pedagógico ou por incidirem em ensino mais efetivo e atrativo. A aplicaçāo de testes de personalidade ou de atitudes era o recurso usado para se constatar a presença ou a aquisiçāo dessas características.

As pesquisas na área consistiam em descobrir, pela aplicaçāo de testes de personalidade ou de opiniāo, quais as características que diferenciavam o comportamento do professor, relacionando-as com o sexo, idade, experiência docente, tempo de formatura etc. Com esse esforço nāo se conseguiram senāo descriçōes da personalidade do professor e o estabelecimento de "modelos ideais" das qualidades tidas como as mais convenientes aos mestres, segundo a opiniāo colhida de grupos de supervisores, pais, alunos e dos próprios professores. Mas, constituiu trabalho interessante por permitir conhecer quais as características distinguiam o professor de outros profissionais, conhecer-lhe a identidade, compará-la à de outros grupos, além de fornecer a tomada de consciência, por parte dos docentes, dessas características enquanto valorizadas e exigidas do bom mestre num dado contexto social. Muitas pesquisas foram feitas nessa direçāo mas, por ficarem em nível puramente descritivo do dizer como é a realidade, tiveram pouca projeçāo na formaçāo dos professores e restrito valor científico enquanto perseguiam uma explicaçāo de "como o professor é", e do "porque compor- ta da forma que o faz".

Por volta dos anos 60/70, a formaçāo do professor, refletindo o espírito tecnicista acentuado na época, se centrou na "aprendizagem para a competência" que dizia respeito nāo só ao aluno como também ao professor. A aquisição da competência em habilidades específicas de ensino, como fazer perguntas, organizar o contexto, conduzir ao fechamento, dar exemplos etc., era ao que se visava.

A formaçāo dos professores e a investigaçāo pedagógica se voltaram para 0 aspecto competência a partir do momento em que qualidades do professor foram postas em relação com os resultados acadêmicos dos alunos e quando se quis fazer descriçōes mais precisas das condutas docentes, estudando sua prática nāo por opiniōes mas analisando a própria docência realizada. A atençāo se voltou para o chamado modelo "processo-produto" que pretendia revelar as relaçōes entre o comportamento dos professores enquanto ensinavam (processo) e as melhorias apresentadas pelos alunos em sua aprendizagem (produto), como conseqüências do "experimentar" a açāo do professor.

Assim, o estudo das qualidades relacionadas ao ensino e à aprendizagem levou ao conceito de competência docente um tipo de condição, de habilidade específica, de conduta particular que se apresenta ligada a um rendimento mais aceitável por parte do aluno e que pode ser indicada como um traço que os professores deveriam ter, aprender ou desenvolver.

Representou um progresso, esse enfoque, tanto para a pesquisa como para a própria formaçāo do professor que passou 
a indicar perspectivas e objetivos mais definidos, apresar das restriçōes que se apresentam, ao tecnicismo como a ênfase demasiada aos detalhes com perda da visāo de conjunto, a despersonalizaçāo, a automaçāo e a alienaçāo do professor que foi alijado do processo de decisāo em seu trabalho, tornando-se apenas um seu executor.

A partir da década de 70, tem-se presenciado, em relaçāo à formaçāo do professor, o esforço de se considerar e de viver na prática a docência como açāo fundamentalmente profissional. Para que uma atividade qualquer possa ser considerada com profissāo, tem-se procurado estabelecer determinados critérios consensualmente aceitos e indicados, tais como: que os métodos e procedimentos empregados pelos membros dessa profissāo derivem de uma base de investigaçōes e conhecimentos teóricos sistematicamente elaborados; que haja subordinaçāo do profissional ao interesse do cliente (como na medicina ou no direito em que a relaçāo profissional-cliente se estabelece no sentido de valorizar o cliente, a ponto de sua cura ou dedicação à sua causa se tornarem pontos vitais de trabalho, além de questōes de honra); que os membros da profissāo se reservem o direito de formular juízos autônomos, no plano individual e no coletivo, isentos de limitaçōes e controles externos, de origem nāo profissional (como na Medicina e no Direito que se regem por códigos de ética próprios, submetendo a avaliaçāo e o julgamento de seus membros ao próprio grupo e que estabelece para si seus procedimentos disciplinares, responsabilidades, etc.); que a profissāo docente seja um trabalho fundamentalmente inte- lectual e, por fim, que conquiste e goze de prestígio e status social reconhecido pela sociedade, justos pela relevância do trabatho que realiza.

Verifica-se, assim, para que o ensino evolua no sentido de uma tarefa genuinamente profissional, como se deseja e se tenta, há necessidade de três tipos de mudanças. As atitudes e práticas docentes devem ter fundamentaçāo teórico-filosófico-científica, advinda da investigaçāo onde o empenho pessoal, ou de grupos, seja substantivamente considerado (competência técnica); que se assuma as responsabilidades profissionais de mestre no sentido da valorizaçāo do "cliente" que é um "usuário-cidadāo", com direitos específicos a partir de um contexto sócio-cultural e político-econômico que deve ser levado em conta (compromisso social); e que se amplie a autonomia profissional dos mestres no sentido de incluí-los nas decisōes do contexto educacional mais amplo em que atuam, além de exigir-lhes que assumam e respondam pelos fazeres que lhes sāo próprios sem se limitarem a meros executores de açōes planejadas por outros (participaçāo).

Assim, um professor nāo nasce pronto e nem se improvisa, "se faz". Aprende-se a sê-lo. O ensinar nāo é "terra de ninguém" ou "terra de todo mundo", campo ao qual se atira sem formaçāo. 0 ensinar é atividade que exige preparo prévio e também preparo continuado, em serviço. Sem se chegar ao domínio de um corpo conceitual determinado inserido num quadro cultural mais amplo, a princípios gerais sobre o ensino, à segurança de execuçāo de operaçōes técnicas específicas de ensino, orientadas por uma visāo e um posicionamento histó- 
rico-filosófico, nāo se pode exercê-lo.

As possibilidades de investigação pedagógica têm se ampliado e enriquecido dentro desse enfoque: os textos de política educativa incorporando os avanços de investigaçāo didática (teorias implícitas); as teorias implícitas no trabalho docente revitalizando a atenção para os processos cognitivos operados pelos professores em açāo; as crenças educativas dos professores como resultado da avaliaçāo efetiva e pessoal do próprio ensino; de como a concepçāo da funçāo sintática, por parte do professor de uma área específica do saber, é vivida na prática; o processo de decisāo evidenciando a riqueza dos esquemas de relaçōes que se estabelecem a partir das coisas percebidas; o conhecimento prático e pessoal dos professores informando e revisando a teoria de sua ação profissional; a aplicaçāo da competência reflexiva em sala de aula como forma de pensar a açāo; de como o docente encarado apenas como técnico reforça o seu caráter de usuário e nāo de proprietário do conhecimento; o desenvolvimento pessoal e profissional como mudanças sofridas pelo professor no tempo; as inovaçōes didáticas enquanto meios de renovaçāo e modificaçāo das funçōes do mestre; a colegialidade como premissa da colaboração e compromisso docente; a elaboraçāo dos mapas conceituais como estratégia de formaçāo e atualizaçāo científico-pedagógica do professor e a formaçāo do pensamento crítico dos professores exigindo a reestruturaçāo dos planos de cursos, sāo veios, além de outros, pelos quais a pesquisa na área têmse evidenciado e endereçado nas perspectivas que a formaçāo de professores vêm assumindo na linha da profissionalizaçāo. Vê-se que nesta terceira fase o sentido da competência se amplia e supera as limitaçōes do tecnicismo, porque se apóia numa compreensāo política da escola e da açāo educativa. A formaçāo do professor é antes um processo, construção, desenvolvimento e tessitura do que simples "aquisiçōes acumuladas". Busca-se autonomia, ou seja, emancipaçāo teórica e prática assentes na competência técnica e no compromisso político nascido da compreensāo da relaçāo Homem/Sociedade/Educaçāo/Escola/Ensino/Aprendizagem.

Portanto, várias razōes justificam a escolha da Formação de Professores como Área de Concentração deste Programa de Mestrado em Educação: a melhoria da qualidade do ensino, que se impōe como necessidade em todos os níveis de escolaridade e exige o aperfeiçoamento docente com vistas à sua efetiva profissionalizaçāo; a natureza da ação didática, cuja complexidade demanda estudos com abordagem multidisciplinar e abre ricas possibilidades para a construção do conhecimento que possa colocar num patamar mais elevado a formação do professor e o desejo de implementar a formação continuada dos docentes das Universidades mantenedoras do Programa. No que se refere à pesquisa, destaca-se o compromisso de produção do conhecimento, relacionado à problemática da Formaçāo de Professores, no âmbito das três linhas de pesquisa delineadas: investigaçāo dos fundamentos sócio-políticos e histórico-filosóficos que têm norteado a formaçāo do professor e a formulaçāo, implantaçāo e gestāo de políticas educacionais. 